\title{
37 Years later: revisiting a Red Sea long-term monitoring site
}
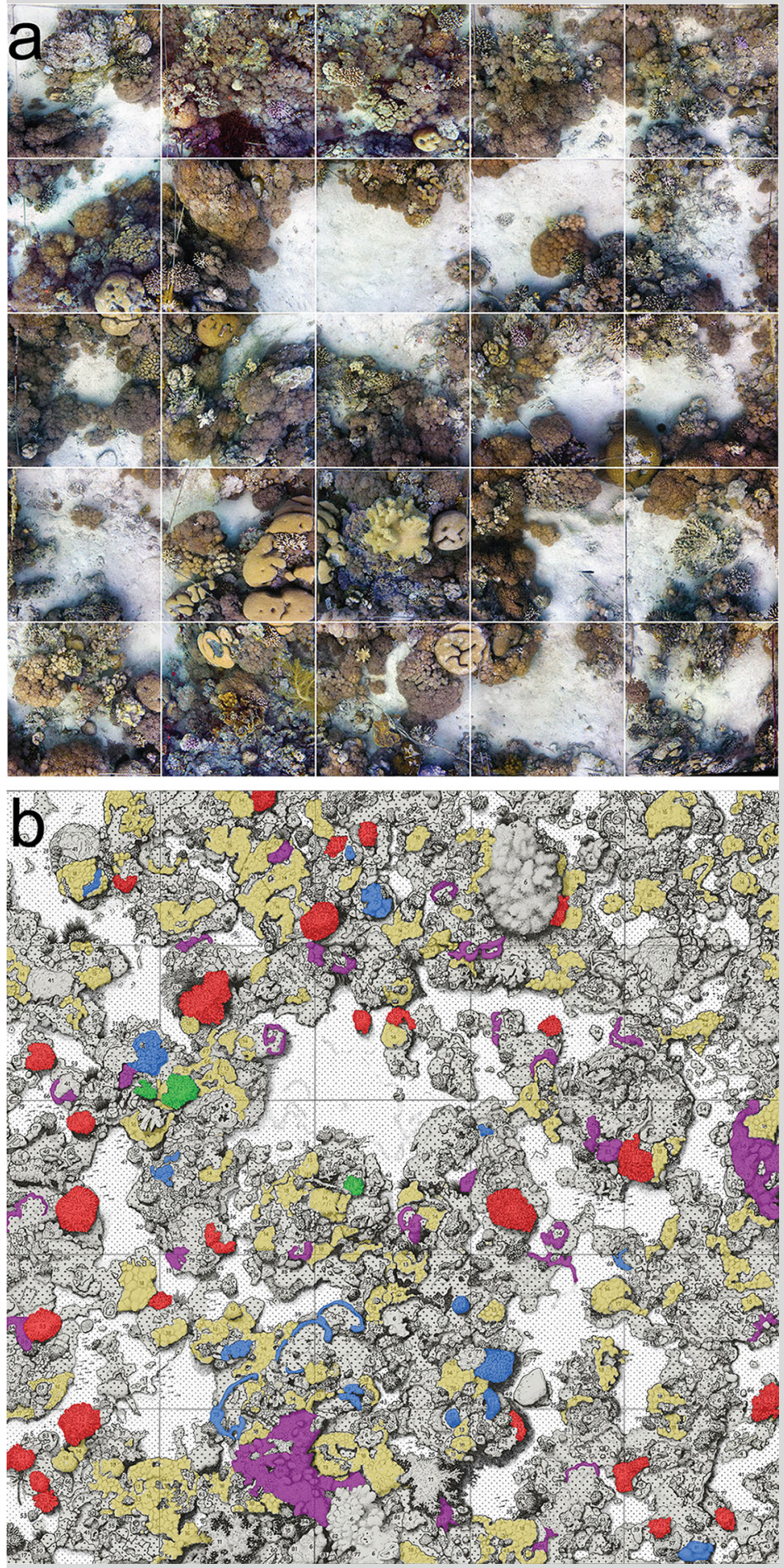

Fig. 1 Benthic community in the quadrat U-7 (size: $5 \times 5 \mathrm{~m}$ ) at $10 \mathrm{~m}$ depth as recorded in a January 2013 and b February 1976. Colors in b indicate large ( $>15 \mathrm{~cm}$ diameter) colonies of Xeniidae (yellow), and branching and massive corals (red and violet, respectively, for colonies that disappeared and green and blue, respectively, for colonies that persisted)
Biodiversity and species abundance in coral reef ecosystems are controlled by structural complexity (Graham and Nash 2013), which is being impacted by reduced net reef framework accretion resulting from anthropogenic stressors (Kennedy et al. 2013). However, evidence verifying changes in benthic reef communities via long-term visual monitoring is rare. In 2013, during an expedition to the northern Red Sea, we revisited a permanent reef quadrat (Fig. 1a, b) located on a fringing reef near Aqaba (Jordan), which was established in 1976 as one of the earliest long-term reef monitoring sites (Mergner and Schuhmacher 1981). High-resolution, sectional photographs were combined to generate a current overview of the benthic community in the entire quadrat (Fig. 1a; Electronic Supplementary Materials, ESM, 1) for a comparison to the initial record (Fig. 1b; ESM 2). The majority of large branching (i.e., Pocilloporidae and Acroporidae) and massive (i.e., Poritidae and Faviidae) hermatypic coral colonies disappeared (Fig. 1b) and were only partially replaced by new ones (ESM 1). Although some massive corals grew noticeably, colony growth in the few persisting branching corals was insubstantial. Overall, hermatypic coral cover declined by $\sim 10 \%$, and ahermatypic cover (mostly Xeniidae) increased by $\sim 15 \%$. These changes were accompanied by a conspicuous increase in sand area $(\sim 10 \%)$ and substantial decrease in bare reef framework $(\sim 20 \%)$, suggesting major structural habitat loss with implications for net reef accretion and associated biodiversity.

\section{References}

Graham NAJ, Nash KL (2013) The importance of structural complexity in coral reef ecosystems. Coral Reefs 32:315-326 Kennedy EV, Perry CT, Halloran PR, Iglesias-Prieto R, Schönberg CHL, Wisshak M, Form AU, Carricart-Ganivet JP, Fine M, Eakin CM, Mumby PJ (2013) Avoiding coral reef functional collapse requires local and global action. Curr Biol 23:912-918 Mergner H, Schuhmacher H (1981) Quantitative Analyse der Korallenbesiedlung eines Vorriffareals bei Aqaba (Rotes Meer). Helgol Wiss Meeresunters 34:337-354

Electronic supplementary material The online version of this article (doi:10.1007/s00338-015-1321-z) contains supplementary material, which is available to authorized users.

\section{U. Cardini (iD $(\bowtie) \cdot$ N. van}

Hoytema $\cdot$ C. Wild $\cdot$ M. S. Naumann

Coral Reef Ecology Group, Leibniz Center for Tropical Marine Ecology (ZMT), Fahrenheitstr. 6, 28359 Bremen, Germany e-mail: ulisse.cardini@gmail.com

M. M. D. Al-Rshaidat

Department of Marine Biology, The University of Jordan -

Aqaba Branch, Aqaba 77110, Jordan

M. M. D. Al-Rshaidat

Laboratory for Molecular Microbial Ecology (LaMME), Marine Science Station, Aqaba 77110, Jordan

\section{H. Schuhmacher}

Faculty of Biology, University of Duisburg-Essen,

Universitätsstr. 5, 45141 Essen, Germany

\section{Wild}

Faculty of Biology and Chemistry, University of Bremen, 28359 Bremen, Germany

Coral Reefs (2015) 34:1111

Received: 12 March 2015/ Accepted: 24 June 2015/Published online: 26 July 2015 DOI $10.1007 / \mathrm{s} 00338-015-1321-\mathrm{Z}$ 